\title{
Jahrestagung 1974
}

25 Jahre nach ihrer Wiederbegründung in Heidelberg hielt die Vereinigung der Deutschen Staatsrechtslehrer ihre Jahrestagung 1974 vom 2. bis 5. Oktober in Bielefeld ab. Den Vorsitz führte Hans Peter Ipsen, die Diskussionen leiteten die Vorstandsmitglieder Klaus Vogel und Fritz Ossenbühl. Das Centrum für interdisziplinäre Forschung (CIF) der Universität bot ideale Verhandlungsräume, die Stadt Bielefeld unterstützte die Durchführung der Tagung ebenso wie das Land NordrheinWestfalen. Der Rektor der Universität begrüßte und bewirtete die Tagungsteilnehmer, ihre Damen und die Gäste der Vereinigung im CIF. Justizminister Dr. Posser als Vertreter der Landesregierung gab einen Abendempfang in der kleinen OetkerHalle.

Die Mitgliederversammlung gedachte der verstorbenen Kollegen Gustav Kafka, Friedrich Klein, Friedrich Glum und Ernst Forsthoff. Zwölf Kollegen sind der Vereinigung im Jahre 1974 beigetreten. Utber die Beratungen des Gesprächskreises Verwaltungslehre berichtete Werner Weber. Der Vorstand wurde für ein weiteres Jahr wiedergewählt. Zur Vorbereitung der Jahrestagung in Augsburg vom 1. bis 4. Oktober 1975 kooptierte der Vorstand Franz Knöpfle.

Nach Abschluß der wissenschaftlichen Arbeit versammelten sich die Tagungsteilnehmer mit ihren Damen im Bültmannshof zum westfälischen Imbiß und tanzten - erstmals in der Geschichte der Vereinigung.

Der traditionelle Sonnabend-Ausflug ging ins Lipperland nach Lemgo, wo die Teilnehmer im Rathaus gastlich empfangen und geführt wurden, danach auf die Burg Blomberg des Landesverbandes Lippe, dessen Vertreter die Aufgaben und Leistungen des Verbandes erläuterte.

Die Tagung nahm wissenschaftlich und in ihren anderen Veranstaltungen einen harmonischen Verlauf. Herrn Frowein, Frau Frowein, Frau Blümel, Herrn Steiner und allen ihren Mitarbeitern gilt der Dank für ihre mühevolle Vorbereitung.

Die nachstehend abgedruckten Referate wurden an den Vormittagen des 3. und 4. Oktober 1974 im CIF der Universität 
Bielefeld gehalten. An den Nachmittagen folgte jeweils die Aussprache. Die Erörterung zentraler Fragestellungen zur 1. und 2. Gewalt, die nach 25jähriger Geltung unseres Grundgesetzes veranlaßt war, soll 1975 auf der Jahrestagung in Augsburg mit solchen zur 3. Gewalt abgerundet werden. 